\title{
Postoperative Nausea and Vomiting in Day Care Patients: A Comparative Randomized Controlled Trial of Total Intravenous Anesthesia with Propofol, Air, and Oxygen vs Inhalation Anesthesia with Isoflurane and Nitrous Oxide
}

\author{
${ }^{1} \mathrm{~A}$ Sandhya, ${ }^{2} \mathrm{R}$ Mamatha, ${ }^{3} \mathrm{Antara}$ Banerjee, ${ }^{4} \mathrm{H}$ Sahajananda
}

\begin{abstract}
Introduction: We compared the incidence of postoperative nausea and vomiting (PONV) after total intravenous anesthesia (TIVA) using propofol-air to inhalational anesthesia with isoflurane-nitrous oxide in day care patients at a tertiary care academic institution.
\end{abstract}

Materials and methods: We randomized 60 patients and assigned to either group I (inhalational anesthesia with isofluranenitrous oxide) or group II (TIVA with propofol-air). Incidence of PONV, use of anti-emetics, and duration of stay in the recovery were recorded for 72 hours by blinded observers.

Results: Total intravenous anesthesia reduced the PONV up to 72 hours by $27 \%$ among our patients (from 37 to $10 \%$, $p<0.001)$. This effect was seen more in the early postoperative period. Overall, $13.3 \%$ of patients in the group I received antiemetic compared to $40 \%$ in group II. In our study, patients without PONV were discharged from the recovery room 15 minutes earlier after TIVA than after isoflurane and $\mathrm{N}_{2} \mathrm{O}$ anesthesia.

Conclusion: Total intravenous anesthesia with propofol and air resulted in a reduction of PONV compared with isoflurane-nitrous oxide anesthesia. Overall, patients in group I required less rescue antiemetic, compared to group II. Total intravenous anesthesia resulted in shorter stay in the postoperative anesthetic care unit compared to isoflurane- $\mathrm{N}_{2} \mathrm{O}$ group.

Keywords: Inhalational anesthesia, Postoperative nausea and vomiting, Total intravenous anesthesia.

How to cite this article: Sandhya A, Mamatha R, Banerjee A, Sahajananda H. Postoperative Nausea and Vomiting in Day Care Patients: A Comparative Randomized Controlled Trial of Total Intravenous Anesthesia with Propofol, Air, and Oxygen vs Inhalation Anesthesia with Isoflurane and Nitrous Oxide. J Med Sci 2015;1(4):63-68.

Source of support: Nil

Conflict of interest: None

\footnotetext{
${ }^{1-3}$ Postgraduate Student, ${ }^{4}$ Professor and Head

${ }^{1-4}$ Department of Anesthesiology, RajaRajeswari Medical College and Hospital, Bengaluru, Karnataka, India
}

Corresponding Author: H Sahajananda, Professor and Head, Department of Anesthesiology, RajaRajeswari Medical College and Hospital, Bengaluru, Karnataka, India, Phone: +919448085401, e-mail: sahaj_anand@hotmail.com

\section{INTRODUCTION}

The use of total intravenous anesthesia (TIVA) using propofol alone or inhalational anesthesia using isoflurane with air and oxygen in day care surgeries is always a matter of concern. ${ }^{1}$ Studies have shown that TIVA with propofol reduces the incidence of postoperative nausea and vomiting (PONV) and results in shorter recovery time..$^{2-6}$ Most of those studies were smaller, did not have follow-up more than 6 hours postoperatively, and many of the studies were sponsored by pharmaceutical companies. The results were difficult to substantiate as a result of multiple definitions of PONV.,8

Hence we compared the incidence of PONV up to 72 hours postoperatively in outpatients who were randomized to receive either inhalational anesthesia with isoflurane- $\mathrm{N}_{2} \mathrm{O}$ or TIVA with propofol-air. The primary aim and hypothesis was that propofol TIVA would probably reduce the incidence of $\mathrm{PONV}$ compared with an inhalation anesthetic technique using isoflurane and $\mathrm{N}_{2} \mathrm{O}$.

\section{MATERIALS AND METHODS}

We conducted a randomized controlled trial of TIVA with propofol $v s$ inhalational anesthesia with isoflurane-air and oxygen. The study was conducted at RajaRajeswari Medical College and Hospital, Bengaluru and was approved by the Institutional Medical Ethics Committee. Sixty patients scheduled to undergo elective surgery under general anesthesia were enrolled in the study. Exclusion criteria were emergency, cardiac, or neurosurgery, American Society of Anesthesiologists physical status classification greater than III, age $<18$ years or $>80$ years, pregnancy, renal or liver disease, use of antiemetic in the 2 weeks before surgery, and body weight more than $120 \mathrm{~kg}$.

\section{PREOPERATIVE EVALUATION}

Preoperative evaluation was done 1 day before the surgery. This involved detailed history from the patient, and any medical complaints that the patient had also noted. General physical examination was done along with a detailed evaluation of the cardiovascular, respiratory, 
and central nervous system. All routine and relevant lab investigations were carried out.

\section{PREOPERATIVE ORDER}

Patients were instructed to stay nil per oral after $10 \mathrm{pm}$. All of them received Tab. alprazolam $0.25 \mathrm{mg}$ orally on the night before surgery. They were given Tab. ranitidine $150 \mathrm{mg}$ orally on the morning of surgery with sips of water and Inj. midazolam $1 \mathrm{mg}$ intravenously (IV) 1 hour before surgery.

All patients were allocated into two groups using computerized randomization table.

Group I: Total intravenous anesthesia with propofol and air.

Group II: Inhalation with isoflurane, nitrous oxide, and oxygen.

Standard monitors were attached along with bispectral index (BIS) monitoring.

In the study (TIVA) group I, general anesthesia was induced with propofol 2 to $3 \mathrm{mg} / \mathrm{kg}$ and maintained on a continuous infusion of 4 to $12 \mathrm{mg} / \mathrm{kg} / \mathrm{hour}$, with $60 \%$ nitrous oxide and $33 \%$ oxygen mixture. The rate of propofol infusion was adjusted according to the need of anesthesia depth by using BIS. Propofol was tapered toward the end of case and stopped at skin closure. Both groups received $0.5 \mathrm{mg} / \mathrm{kg}$ atracurium for intubation and further maintained on one-third of the original dose, as top-up doses. Intraoperatively, analgesia in both the groups was provided with $2 \mu \mathrm{g}$ of fentanyl at induction, along with multimodal analgesia using paracetamol $1 \mathrm{~g}$ IV, $75 \mathrm{mg}$ of Inj. diclofenac, and infiltration analgesia before skin incision.

In this study, the symptoms of PONV, such as nausea, retching, and vomiting, were observed and the severity of PONV was rated at timely intervals. Use of antiemetics, pain scores [visual analog scale (VAS) score], patient satisfaction scores, and time of discharge from the recovery area were also noted.

\section{Monitoring}

Intraoperative heart rate (HR), blood pressure (BP), $\mathrm{EtCO}_{2}$, and electrocardiogram (ECG) were monitored continuously. The duration of surgery was noted.

Postoperatively, patients were observed for 24,48 , and 72 hours for nausea, retching, and vomiting.

Pain was assessed using VAS score; in case VAS score exceeded $4 / 5$, patients were given rescue analgesia as Inj. diclofenac $75 \mathrm{mg}$ IM.

Rescue antiemetic comprised $0.15 \mathrm{mg} / \mathrm{kg}$ metoclopramide IV and was given if patients were having retching. Rescue antiemetic doses if given were also noted. Complications if any were also noted.

\section{Postoperative Assessment: Measurements}

Routine monitoring was initiated on arrival in the postoperative anesthetic unit (PACU) or day care unit. Every 15 minutes, anesthesiologist recorded PONV, use of analgesic, and antiemetic medication. Nausea, retching, and vomiting were scored separately.

In the postoperative period, the patients were monitored for the 1st 24 hours:

They were monitored for:

- Episodes of nausea: Defined as a subjective unpleasant feeling of having to vomit. This was scored 0 to 3 .

$0=$ no nausea

$1=$ mild nausea

$2=$ moderate nausea

$3=$ severe nausea

- Episode of retching was defined as vomiting movement without actual vomiting, which was scored as absent or present.

- They were also observed for episodes of vomiting, that is expulsion of stomach contents, and whether they had early or late PONV.

- A cumulative PONV score was calculated taking into account nausea, vomiting, and retching scores.

- The patients were also assessed for pain using the VAS for the 1st 24 hours.

- Approximately 24 hours after surgery, an anesthesiologist visited patients in the ward or telephoned outpatients at home to record occurrence of PONV, use of antiemetics or analgesics, and the presence of possible postoperative complications and side effects subsequent to discharge from the PACU. The time of discharge and duration of stay in the recovery area were also noted. Patients were asked to quantify discomfort caused by nausea, retching, and vomiting and to rate their anesthetic experience (in the scale of 0-10). Similar information was collected 72 hours postoperatively with reference to the previous 48 hours.

\section{STATISTICAL ANALYSIS}

Data were collected and entered in MS Excel and analyzed using Statistical Package for the Social Sciences (SPSS) version 2.0. Descriptive statistics includes frequencies, percentages, and mean with standard deviation. Student's t-test will be used to test the significant difference between the two groups with $95 \%$ confidence interval.

Sample size is calculated to be $66 ; 33$ in each group by the formula

$$
n=4 P Q / L^{2}
$$

where $\mathrm{P}=$ prevalence of $\mathrm{PONV}$ in gynecological patients undergoing laparoscopic surgeries, i.e., 75\%; Q=100-P; $\mathrm{L}=$ allowable error. (20\% of P). 


\section{RESULTS}

Six patients were excluded from the study as they could not be contacted for the follow-up after 24 hours.

Baseline patient characteristics were similar across allocation groups (Table 1). The average age of patients was 60.10 and 59.20 years respectively. The mean BMI in group I was $24.85 \pm 4.75$ as against $24.66 \pm 3.42$ in group II with a $\mathrm{p}$ value of 0.856 , which was statistically insignificant.

\section{Types of Surgery}

In all the groups duration of anesthesia and surgery were also similer and not signifcant (Graphs 1 and 2). The mean duration of surgery was $87.50 \pm 31.07$ in group I as against $87.44 \pm 27.47$ in group II. Average duration of

Table 1: Demographic data - mean (SD)

\begin{tabular}{llll}
\hline & Group I & Group II & $p$-value \\
\hline Age (years) & $60.10 \pm 13.60$ & $59.20 \pm 9.64$ & 0.769 \\
Height $(\mathrm{cm})$ & $155.03 \pm 5.49$ & $154.73 \pm 5.72$ & 0.837 \\
BMI $\left(\mathrm{kg} / \mathrm{m}^{2}\right)$ & $24.85 \pm 4.75$ & $24.66 \pm 3.42$ & 0.856 \\
\hline
\end{tabular}

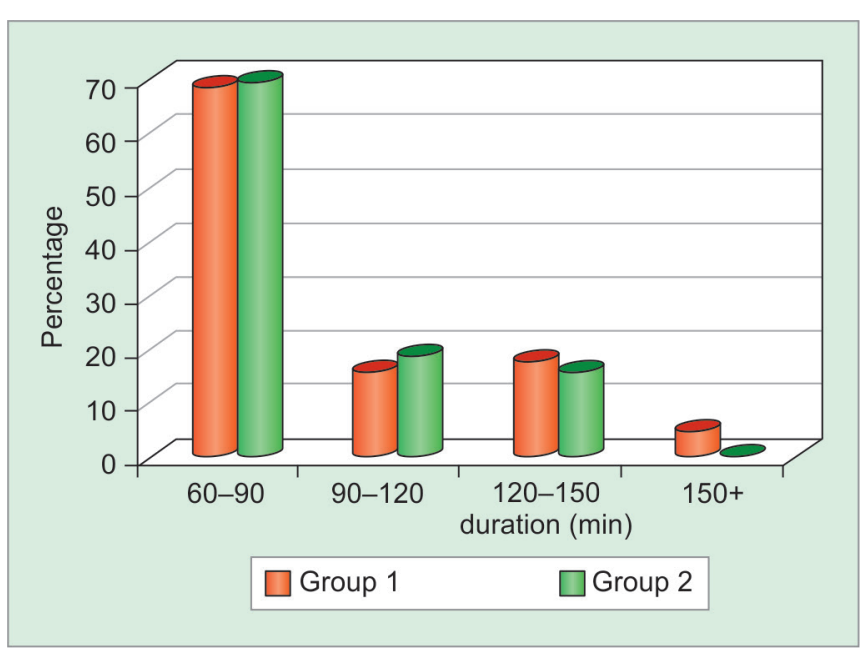

Graph 1: Duration of surgery (minutes)

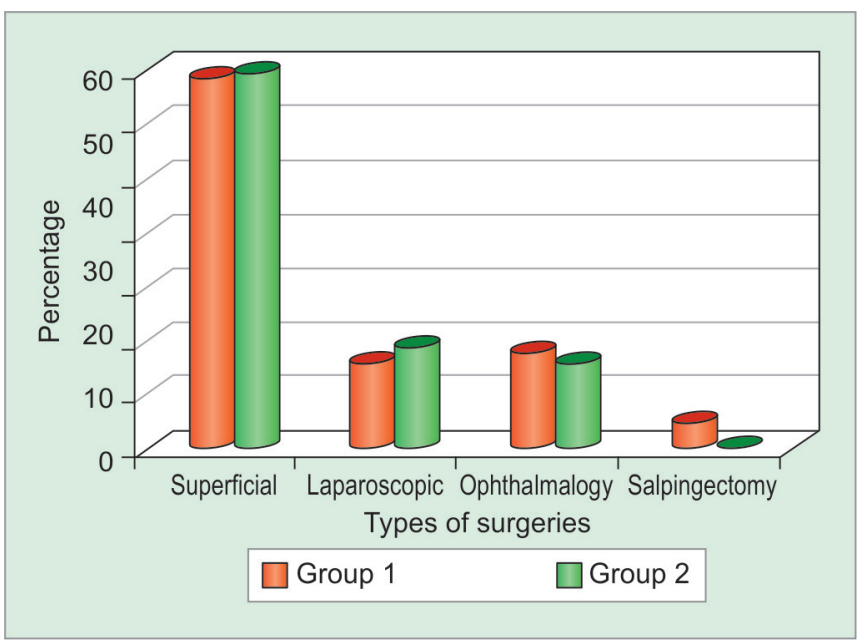

Graph 3: Types of surgery surgery for both groups was 60 to 90 minutes. This was found to be statistically insignificant.

In group I out of a total of 30, 16 patients underwent superficial surgeries, 9 underwent Diagnostic Hysteroscopic Laproscopy, 3 underwent cystoscopy, 1 underwent salpingectomy and 1 underwent cystectomy. While in group II out of the total 30, 15 patients underwent superficial surgeries, 13 underwent Diagnostic Hysteroscopic Laproscopy, 1 underwent cystoscopy, 1 underwent salpingectomy. The p-value for the type of surgery done was not found to be significant (Graph 3).

The mean dose of fentanyl in group I was $101.33 \pm 17.95$ as compared to $97.67 \pm 14.06$ in group II, this was found to have a $\mathrm{p}$ value of 0.382 , which was not statistically significant (Graph 4).

Hence the two groups were well randomized and statistically comparable in terms of age, sex, weight, duration of surgery, anesthesia, types of surgery, and opioid use in our study.

Endotracheal tubes and muscle relaxants were used for all patients. All patients received opioids intraoperatively.

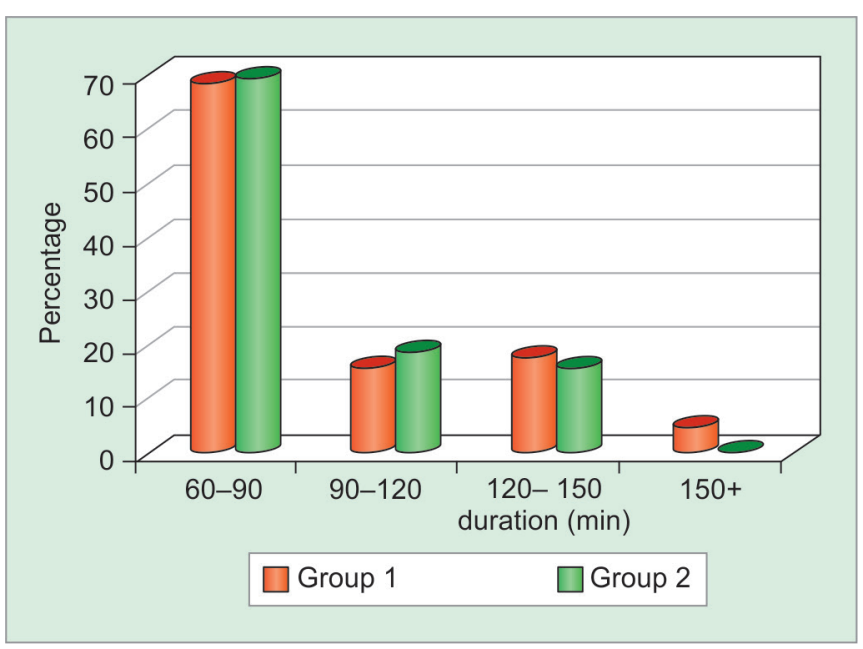

Graph 2: Duration of anesthesia (minutes)

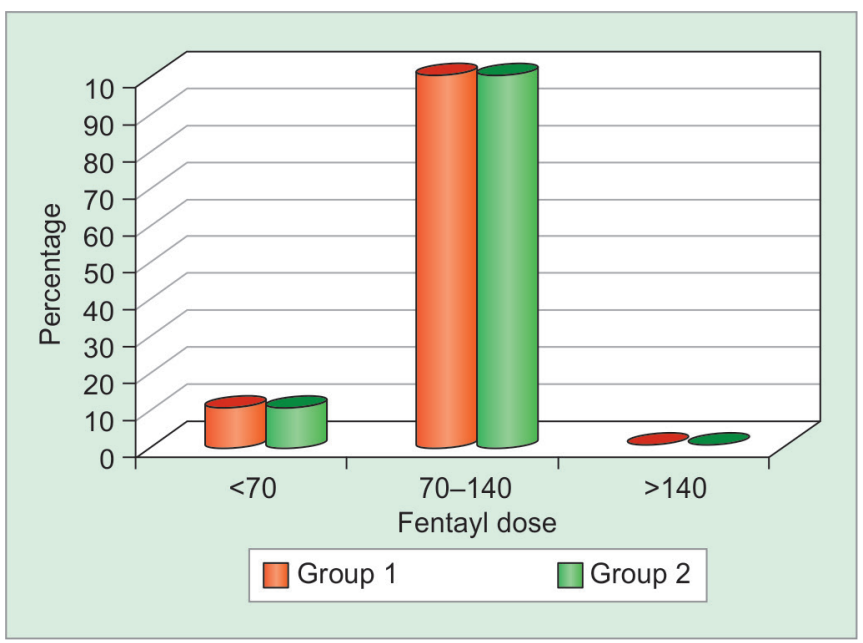

Graph 4: Fentanyl dose $(\mu \mathrm{g})$ 
The average use of propofol for anesthesia maintenance was $10.0 \mathrm{mg} / \mathrm{kg} /$ hour. Isoflurane use was $12.5 \mathrm{~mL} /$ hour. The time from discontinuation of anesthesia until response to a verbal command in outpatients after TIVA or isoflurane was 9 minutes.

\section{Postoperative Nausea and Vomiting}

\section{Nausea}

In group I, $10 \%$ of patients had nausea compared to group II who had $36.7 \%$ in the 1st 24 hours. It was statistically significant $(p=0.029)$. In the next 48 hours and at 72 hours, the incidence of nausea was not significant (Table 2).

\section{Retching}

Incidence of retching between the two groups was not significant over 24 hours (Table 3 ).

\section{Vomiting}

Incidence of vomiting was more in group I compared to group II at 24 hours and statistically it was significant (Table 4); whereas at 48 and 72 hours incidence, it was not significant.

Table 2: Incidence of nausea in numbers (percentages)

\begin{tabular}{lllll}
\hline Nausea & 24 hours & 48 hours & 72 hours & $\%$ Change \\
\hline Group I $(n=30)$ & & & & \\
0 & $27(90 \%)$ & $28(93.3 \%)$ & $30(100 \%)$ & 10.0 \\
1 & $1(3.3 \%)$ & $0(0 \%)$ & $0(0 \%)$ & 0.0 \\
2 & $0(0 \%)$ & $2(6.7 \%)$ & $0(0 \%)$ & -3.3 \\
3 & $2(6.7 \%)$ & $0(0 \%)$ & $0(0 \%)$ & -6.7 \\
Group II $(n=30)$ & & & & \\
0 & $19(63.3 \%)$ & $29(96.7 \%)$ & $30(100 \%)$ & 36.7 \\
1 & $1(3.3 \%)$ & $0(0 \%)$ & $0(0 \%)$ & -23.3 \\
2 & $6(20 \%)$ & $0(0 \%)$ & $0(0 \%)$ & -13.3 \\
3 & $4(13.3 \%)$ & $1(3.3 \%)$ & $0(0 \%)$ & 0.0 \\
p-value & $0.029 *$ & 0.492 & 1.000 & - \\
\hline
\end{tabular}

* Moderately Significant

Table 4: Incidence of vomiting numbers (percentages)

\begin{tabular}{llll}
\hline Vomiting & 24 hours & 48 hours & 72 hours \\
\hline Group II $(n=30)$ & & & \\
No & $25(83.33 \%)$ & $28(93.33)$ & $29(96.7 \%)$ \\
Yes & $5(16.66 \%)$ & $2(6.67 \%)$ & $1(3.3 \%)$ \\
Group I $(n=30)$ & & & \\
No & $28(93.33 \%)$ & $29(96.7)$ & $29(96.7 \%)$ \\
Yes & $2(6.67 \%)$ & $1(3.3 \%)$ & $1(3.3 \%)$ \\
p-value & 0.001 & 0.453 & 1.000 \\
\hline
\end{tabular}

\section{PONV Score}

The overall incidence of vomiting between the two groups was significant at 24 hours $(p=0.001)$. It was not significant at 48 and 72 hours (Table 5).

\section{Rescue Antiemetic}

Overall, four patients in group I required rescue antiemetic, while 12 in group II needed rescue antiemetic. Requirement of rescue antiemetic between the two groups was not significant statistically (Table 6).

\section{Pain}

Following surgery, the pain scores between the two groups were comparable, and not statistically significant.

\section{DISCUSSION}

Postoperative nausea and vomiting are common and distressing to patients, with an incidence of as high as $80 \%$ in high-risk patients. According to the 2014 consensus guidelines for the management of PONV by the American Society of Anesthesiologist, the first step in management is identification of high-risk individuals. Of the various scoring systems, the Apfel risk score is one of

Table 3: Incidence of retching numbers (percentages)

\begin{tabular}{lllll}
\hline Retching & 0-24 hours & 48 hours & 72 hours & \% Change \\
\hline \multicolumn{2}{l}{ Group I $(n=30)$} & & & \\
No & $28(93.3 \%)$ & $27(90 \%)$ & $28(93.3 \%)$ & 10.0 \\
Yes & $2(6.7 \%)$ & $3(10 \%)$ & $2(6.7 \%)$ & -10.0 \\
Group II $(n=30)$ & & & \\
No & $23(76.7 \%)$ & $30(100 \%)$ & $26(86.7 \%)$ & 0.0 \\
Yes & $7(23.3 \%)$ & $0(0 \%)$ & $4(13.3 \%)$ & 0.0 \\
p-value & 0.145 & 0.237 & 0.671 & - \\
\hline
\end{tabular}

Table 5: Incidence of PONV in numbers (percentages)

\begin{tabular}{|c|c|c|c|c|}
\hline PONV score & 24 hours & 48 hours & 72 hours & $\%$ Change \\
\hline \multicolumn{5}{|c|}{ Group I $(n=30)$} \\
\hline 0 & $27(90 \%)$ & $28(93.3 \%)$ & $30(100 \%)$ & 6.7 \\
\hline 1 & $0(0 \%)$ & $0(0 \%)$ & $0(0 \%)$ & 0.0 \\
\hline 2 & $0(0 \%)$ & $0(0 \%)$ & $0(0 \%)$ & 0.0 \\
\hline 3 & $0(0 \%)$ & $1(3.3 \%)$ & $0(0 \%)$ & -3.3 \\
\hline 4 & $2(6.7 \%)$ & $0(0 \%)$ & $0(0 \%)$ & 0.0 \\
\hline 5 & $1(3.3 \%)$ & $1(3.3 \%)$ & $0(0 \%)$ & -3.3 \\
\hline \multicolumn{5}{|c|}{ Group II $(n=30)$} \\
\hline 0 & $19(63.3 \%)$ & $23(76.7 \%)$ & $28(93.3 \%)$ & 20.0 \\
\hline 1 & $7(23.3 \%)$ & $0(0 \%)$ & $0(0 \%)$ & -13.3 \\
\hline 2 & $0(0 \%)$ & $3(10 \%)$ & $0(0 \%)$ & -13.3 \\
\hline 3 & $0(0 \%)$ & $0(0 \%)$ & $0(0 \%)$ & 0.0 \\
\hline 4 & $0(0 \%)$ & $1(3.3 \%)$ & $1(3.3 \%)$ & 3.3 \\
\hline 5 & $4(13.3 \%)$ & $3(10 \%)$ & $1(3.3 \%)$ & 3.3 \\
\hline$p$-value & $0.001^{*}$ & 0.150 & 0.492 & - \\
\hline
\end{tabular}


Table 6: Use of antiemetics in numbers and percentages

\begin{tabular}{lllllll}
\hline & \multicolumn{3}{l}{ Group I $(n=30)$} & & \multicolumn{3}{c}{ Group II $(n=30)$} \\
\cline { 2 - 3 } \cline { 6 - 7 } Rescue antiemetic & No & $\%$ & & No & $\%$ & p-value \\
\hline 24 hours & 1 & 3.3 & 2 & 6.7 & 1.000 \\
48 hours & 1 & 3.3 & & 4 & 13.3 & 1.000 \\
72 hours & 1 & 3.3 & 4 & 13.3 & 1.000 \\
& 4 & 13.3 & 12 & 40 & \\
\hline
\end{tabular}

the commonly used ones. It is based on four predictors, such as female sex, nonsmokers, patients with a previous history of PONV, and who are on opioid drugs. Patients with three or more risk factors are considered at high risk for PONV. Our study included a moderate- to high-risk population, i.e., females in the age group 25 to 40 years who are nonsmokers and not on any opioids.

Strategies to reduce the baseline risk are by using regional anesthesia over general, propofol induction, avoiding nitrous oxide and volatile anesthetics, minimizing the use of opioids perioperatively and use of good hydration. Patients in our study were all induced with propofol and a single dose of fentanyl at induction. General anesthesia, volatile agents like isoflurane and use of nitrous oxide were factors which could not be avoided.

We compared and studied the incidence of PONV up to 72 hours postoperatively in day care patients at a tertiary care academic institution who were randomized to receive either inhalational anesthesia with isoflurane$\mathrm{N}_{2} \mathrm{O}$ or TIVA with propofol-air.

Our study and control groups were both comparable demographically. Duration of anesthesia (Graphs 1 to 3) and intraoperative (Graph 4) and post operative analgesia (Table 7) was comparable between the two groups.

In our study, the incidence of PONV was significantly lower after TIVA than after isoflurane. In TIVA group I, absolute risk reduction was between $27 \%$, which depends on the duration of follow-up. Moreover, in patients' view, TIVA was superior to isoflurane with $\mathrm{N}_{2} \mathrm{O}$. The reduction in PONV in our study is in agreement with results from two recent meta-analyses by Tramer et $\mathrm{al}^{7}$ and Sneyd et $\mathrm{al}^{8}$ comparing propofol with isoflurane inhalational agent. Follow-up period in our study was long enough compared with few other PONV studies. We think that the anesthetic technique in the 1 st 24 hours after surgery, probably, has reduced the incidence of PONV. At 48 and 72 hours, the incidence of PONV increased equally in both groups, hence suggests that

Table 7: Mean visual analog score (SD)

\begin{tabular}{llll}
\hline Pain & Group I & Group II & $p$-value \\
\hline 24 hours & $3.17 \pm 1.05$ & $3.17 \pm 0.99$ & 1.000 \\
48 hours & $3.63 \pm 0.96$ & $4.03 \pm 0.89$ & 0.100 \\
72 hours & $3.00 \pm 0.95$ & $3.17 \pm 1.05$ & 0.522 \\
\hline
\end{tabular}

the anesthetic technique influences the PONV in the 1st 24 hours after surgery, whereas PONV resulting from the surgery and analgesics in the postoperative period dominates thereafter.

Various definitions of PONV have been used, e.g., retching, nausea only, nausea and vomiting, or vomiting only. This in turn has led to difficulties in comparing the various studies. ${ }^{9,10}$ In our study, we scored nausea, retching, and vomiting separately.

Antiemetics were administered more often in patients who received isoflurane than TIVA, 40 vs 13.3\%. Subjective ratings of patient satisfaction were highest at 24 hours in the TIVA group. Even after 48 and 72 hours, the ratings of patient satisfaction in general were higher for TIVA than for isoflurane.

All our patients received propofol for induction. Propofol used for anesthesia induction has antiemetic property. This should have reduced the incidence of $P O N V$, irrespective of the maintenance regimen. It is not the case in the present study. This finding is in agreement with the results from a meta-analysis by Tramer et al. ${ }^{7}$

They showed that propofol for anesthesia induction followed by a nonpropofol maintenance technique did not result in the reduction of PONV. Many authors have used $\mathrm{N}_{2} \mathrm{O}$ during propofol anesthesia. The use of $\mathrm{N}_{2} \mathrm{O}$ allows for lower propofol infusion rates ${ }^{11,12}$ in TIVA and reduces the incidence of awareness during anesthesia and intraoperative period. ${ }^{13}$ It is said that $\mathrm{N}_{2} \mathrm{O}$ may increase the incidence of PONV. ${ }^{14}$ A recent meta-analysis by Divatia et $\mathrm{al}^{15}$ has also substantiated this view.

In our study protocol, patients are required to remain in the PACU for at least 1 hour. We found that patients without PONV were discharged from the recovery room 15 minutes earlier after TIVA than after isoflurane. This has also been reported by other investigators. ${ }^{16,17}$

\section{DRAWBACKS OF THE STUDY}

This study was conducted in a single academic institution and these results need to be validated. Further, large-scale clinical trials are required.

\section{CONCLUSION}

Total intravenous anesthesia with propofol compared to isoflurane with $\mathrm{N}_{2} \mathrm{O}$ was associated with a significantly reduced rate of PONV in the 1st 24 hours and reduced antiemetic consumption. Total intravenous anesthesia increases patient comfort and patient ratings of anesthesia, while slightly reducing discharge time.

\section{REFERENCES}

1. Visser K, Hassink EA, Bonsel GJ, Moen J, Kalkman CJ. Randomized controlled trial of total intravenous anesthesia 
with propofol $v$ s inhalation anesthesia with isoflurane-nitrous oxide: postoperative nausea and vomiting and economic analysis. Anesthesiology 2001 Sep;95(3):616-626.

2. Borgeat A, Wilder-Smith OH, Saiah M, Rifat K. Subhypnotic doses of propofol possess direct antiemetic properties. Anesth Analg 1992 Apr;74(4):539-541.

3. Kalman SH, Jensen AG, Ekberg K, Eintrei C. Early and late recovery after major abdominal surgery: comparison between propofol anaesthesia with and without nitrous oxide and isoflurane anaesthesia. Acta Anaesthesiol Scand 1993 Nov;37(8):730-736.

4. Raftery S, Sherry E. Total intravenous anaesthesia with propofol and alfentanil protects against postoperative nausea and vomiting. Can J Anaesth 1992 Jan;39(1):37-40.

5. Oddby-Muhrbeck E, Jakobsson J, Andersson L, Askergren J. Postoperative nausea and vomiting: a comparison between intravenous and inhalation anaesthesia in breast surgery. Acta Anaesthesiol Scand 1994 Jan;38(1):52-65.

6. Klockgether-Radke A, Piorek V, Crozier T, Kettler D. Nausea and vomiting after laparoscopic surgery: a comparison of propofol and thiopentone/halothane anaesthesia. Eur J Anaesthesiol 1996 Jan;13(1):3-9.

7. Tramer M, Moore A, McQuay H. Propofol anaesthesia and postoperative nausea and vomiting: quantitative systematic review of randomized controlled studies. Br J Anaesth 1997 Mar;78(3):247-255.

8. Sneyd JR, Carr A, Byrom WD, Bilski AJ. A meta-analysis of nausea and vomiting following maintenance of anaesthesia with propofol or inhalational agents. Eur J Anaesthesiol 1998 Jul;15(4):433-445.
9. Korttila K. The study of postoperative nausea and vomiting. Br J Anaesth 1992;69(7 Suppl 1):20S-23S.

10. Andrews PL. Physiology of nausea and vomiting. Br J Anaesth 1992;69(7 Suppl 1):2S-19S.

11. Davidson JA, Macleod AD, Howie JC, White M, Kenny GN. Effective concentration 50 for propofol with and without 67\% nitrous oxide. Acta Anaesthesiol Scand 1993 Jul;37(5): 458-464.

12. Raeder JC. Total intravenous anaesthesia - free from nitrous oxide, free problems? Acta Anaesthesiol Scand 1994 Nov;38(8): 769-770.

13. Tramer M, Moore A, McQuay H. Omitting nitrous oxide in general anaesthesia: meta-analysis of intraoperative awareness and postoperative emesis in randomized controlled trials. Br J Anaesth 1996 Feb;76(2):186-193.

14. James MFM. Nitrous oxide: still useful in the year 2000? Curr Opin Anaesthesiol 1999 Jul;12(4):461-466.

15. Divatia JV, Vaidya JS, Badwe RA, Hawaldar RW. Omission of nitrous oxide during anesthesia reduces the incidence of postoperative nausea and vomiting: a meta-analysis. Anesthesiology 1996 Nov;85(5):1055-1062.

16. Boldt J, Muller M, Uphus D, Hempelmann G. Cost aspects in anesthesia: propofol vs isoflurane anesthesia [Article in German]. Anaesthetist 1996 Aug;45(8):731-736.

17. Phillips AS, Mirakhur RK, Glen JB, Hunter SC. Total intravenous anaesthesia with propofol or inhalational anaesthesia with isoflurane for major abdominal surgery: recovery characteristics and postoperative oxygenation - an international multicentre study. Anaesthesia 1996 Nov;51(11): 1055-1059. 